\title{
Age differences in conscious versus subconscious social perception: The influence of face age and valence on gaze following
}

\author{
Phoebe E. Bailey $^{1 *}$, Gillian Slessor ${ }^{2}$, Peter G. Rendell ${ }^{3}$, Rachel J. Bennetts ${ }^{4}$, Anna Campbell ${ }^{5}$, \\ and Ted Ruffman ${ }^{5}$ \\ ${ }^{1}$ School of Social Sciences and Psychology, University of Western Sydney, Australia \\ ${ }^{2}$ School of Psychology, University of Aberdeen, UK \\ ${ }^{3}$ School of Psychology, Australian Catholic University, Melbourne, Australia \\ ${ }^{4}$ School of Design, Engineering, and Computing, Bournemouth University, UK \\ ${ }^{5}$ Department of Psychology, University of Otago, New Zealand
}

*Corresponding author:

Phoebe E. Bailey

School of Social Sciences and Psychology

University of Western Sydney

Locked Bag 1797

Penrith NSW 2751

AUSTRALIA

Phone: +61 (2) 97726230

Email: p.bailey@uws.edu.au 


\begin{abstract}
Gaze following is the primary means of establishing joint attention with others and is subject to age-related decline. In addition, young but not older adults experience an own-age bias in gaze following. The current research assessed the effects of subconscious processing on these agerelated differences. Participants responded to targets that were either congruent or incongruent with the direction of gaze displayed in supraliminal and subliminal images of young and older faces. These faces displayed either neutral (Study 1), or happy and fearful (Study 2) expressions. In Studies 1 and 2, both age groups demonstrated gaze-directed attention by responding faster to targets that were congruent as opposed to incongruent with gaze-cues. In Study 1, subliminal stimuli did not attenuate the age-related decline in gaze-cuing, but did result in an own-age bias among older participants. In Study 2, gaze-cuing was reduced for older relative to young adults in response to supraliminal stimuli, and this could not be attributed to reduced visual acuity or age group differences in the perceived emotional intensity of the gaze-cue faces. Moreover, there were no age differences in gaze-cuing when responding to subliminal faces that were emotionally arousing. In addition, older adults demonstrated an own-age bias for both conscious and subconscious gaze-cuing when faces expressed happiness but not fear. We discuss growing evidence for age-related preservation of subconscious relative to conscious social perception, as well as an interaction between face age and valence in social perception.
\end{abstract}

Keywords: gaze-directed attention, subconscious processing, own-age bias; emotion; aging

Word count: 8,263 


\section{Age differences in conscious versus subconscious social perception: The influence of face age and valence on gaze following}

Joint attention is a basic component of social perception that allows us to identify where or what someone is attending to, and to orient to the same thing. It not only drives simple everyday social communication, but is also a critical precursor to more complex social perceptual abilities such as making inferences about the mental states of others (i.e., theory of mind) and comprehending their emotions (Charman et al., 2000). The primary means of establishing joint attention with others is by following their gaze (Driver et al., 1999). Indeed, those with reduced capacity for emotion recognition and theory of mind, such as older adults (for reviews see, Henry, Phillips, Ruffman, \& Bailey, 2013; Moran, 2013; Ruffman, Henry, Livingstone, \& Phillips, 2008), are also less adept at following gaze-cues (Slessor, Laird, Phillips, Bull, \& Filippou, 2010; Slessor, Phillips, \& Bull, 2008). While both young and older adults successfully follow the gaze of others, demonstrating a gaze-congruity effect (i.e., responding more quickly to target locations that are predicted by gaze direction compared to those that are incongruent with gaze-cues; Driver et al., 1999), this congruity effect is smaller among older adults.

\section{Conscious and subconscious components of gaze-directed attention}

It has been suggested that, rather than demonstrating impairment in gaze following, the reduced gaze-congruity effect with age might actually reflect an improvement in strategic allocation of attention. That is, older adults may be enacting strategic skills to locate the targets, such as avoiding looking at the eye region of gaze-cue faces or ignoring gaze-cues altogether. These conscious strategies, rather than an inherent difficulty in gaze following, are therefore suggested to be the cause of older adults' smaller gaze-congruity effect. On the one hand, this explanation can potentially be discounted since inhibitory control, which would be required to 
ignore a gaze-cue, decreases with age (Cohn, Dustman, \& Bradford, 1984; Kane, Hasher, Stoltzfus, Zacks, \& Connelly, 1994). Nevertheless, the explanation is plausible because when making other social judgments from the face region, such as interpreting facial expressions, young adults generally focus on the eye region, while older adults fixate on the mouth region (Murphy \& Isaacowitz, 2010; Sullivan, Ruffman, \& Hutton, 2007; Wong, Cronin-Golomb, \& Neargarder, 2005, but see He et al., 2011). It is therefore feasible that this lack of attention to the eye region may be a contributor to the age-related decline in gaze-directed attention.

Although it has been claimed that strategic control may be exerted over gaze-directed attention, it has also been argued that, under certain conditions, gaze following is a reflexive and automatic process that is beyond intentional suppression (Langton \& Bruce, 1999, although see Ristic \& Kingstone, 2005). For instance, young adults tend to orient their attention in response to another's gaze direction even when they are specifically instructed that gaze does not predict target location (Okada et al., 2008). Young adults also respond appropriately to subliminal gazecues that they are not consciously aware of (Sato, Okada, \& Toichi, 2007; Sato, Uono, Okada, \& Toichi, 2010). Taken together, achieving joint attention via eye gaze can be a reflexive and automatic process occurring without conscious awareness of the gaze cue.

\section{Aging and subconscious social perception}

To date, all assessments of age differences in the gaze-congruity effect have been based on conscious processing abilities in response to supraliminal stimuli (i.e., Slessor et al., 2008, 2010). However, there is growing evidence that the difficulty older adults exhibit in responding appropriately to some social and emotional information may be attenuated or eliminated in the context of more automatic processing. For example, although older adults do not perform as well as younger adults when asked to label expressions of anger (Ruffman et al., 2008), they have no 
difficulty rapidly detecting those expressions, which is a biologically significant, and thus more automatic response to threat (Mather \& Knight, 2006; Ruffman, Ng, \& Jenkin, 2009). Agerelated declines in theory of mind are also more evident as conscious, controlled processing demands are increased (Bailey \& Henry, 2008). Similarly, labeling and subconsciously mimicking facial expressions represent components of affective empathy that are controlled versus automatic, respectively (Singer \& Lamm, 2009). While older adults have difficulty with the former (Ruffman et al., 2008), they are as proficient as young in the latter (Bailey \& Henry, 2009). There is also a sparing of subconscious mimicry (Bailey \& Henry, 2009) which contrasts with age-related disruption of later, more conscious stages of facial expression mimicry (Bailey, Henry, \& Nangle, 2009).

This emerging relation between preservation of social perception and increasing automaticity of a task in older adulthood is consistent with a larger body of research demonstrating the same relation in older adults' cognitive processes, such as memory and inhibitory control. Specifically, more automatic cognitions requiring fewer processing resources are spared with age relative to cognitions that require greater strategic and deliberative processing (e.g., Craik \& Salthouse, 2000; Fleischman, Wilson, Gabrieli, Bienias, \& Bennett, 2004; Jennings \& Jacoby, 1993; Phillips \& Henry, 2005). The current study aimed to delineate whether following eye gaze might be an aspect of social perception that is relatively more preserved with age as the requirements for controlled cognitions decrease. This would provide the first direct, within-subjects comparison of age differences in conscious versus subconscious social perception.

\section{Face age in social perception}


An emerging finding in the social perception literature is that the age of a face influences whether and how faces are attended to (Ebner \& Johnson, 2010). It has been suggested that ownage faces are more likely to represent potential interaction partners (Ebner \& Johnson, 2010; Wright et al., 2008), and as noted, establishing joint attention via eye gaze is a component of social perception that is a critical precursor to successful social interactions. This suggests that the gaze of one's own age group may be prioritized. Indeed, several factors influence gaze-cuing responses, including the identity of the person displaying the gaze-cue. Young adults demonstrate stronger gaze cuing effects in response to someone they are familiar with (Deaner, Shepherd, \& Platt, 2007), or who aligns with their political affiliation (Liuzza et al., 2011), and are more likely to follow the gaze of a young than an older face (Slessor et al., 2010). This latter finding was suggested to reflect the greater experience people have interacting with own-age than other-age individuals (Ebner \& Johnson, 2010; He, Ebner, \& Johnson, 2011; Wright et al., 2008). Although this own-age bias in gaze following was found only for young adults, a recent meta-analysis demonstrated that the own-age bias exists for face recognition in various age groups, including older adults (Rhodes \& Anastasi, 2012). Further research may therefore be required to better understand the role of face age in young and older adults' gaze following.

\section{Study 1}

In Study 1, we compared gaze-cuing when viewing young and older faces both subliminally and supraliminally. To the best of our knowledge, no study has previously examined age-related responding to such contrasting stimuli. It was predicted that gaze-congruity effects would be smaller for older relative to young adults in response to supraliminal, but not subliminal, cues. It was unclear whether an own-age bias in gaze following would be seen for 
only young adults, in line with Slessor et al. (2010), or whether both age groups would demonstrate this effect, consistent with Rhodes and Anastasi (2012).

\section{Method}

\section{Participants}

Participants were 35 young $(M=20.31$ years, $S D=2.26$; range $18-26)$ and 34 older adults $(M=70.52$ years, $S D=4.67$; range $65-84)$. The young adults were undergraduate students at the University of Western Sydney participating in exchange for course credit. The older adults were recruited from the community via local newspaper advertisements and flyers at local libraries and were reimbursed \$20 Australian ( USD20) per hour to cover out-of-pocket expenses. Exclusion criteria included a self-reported history of psychiatric or neurological impairment, and all older participants scored above 25 on the Mini-Mental State Examination (MMSE; Folstein, Folstein, \& McHugh, 1975). All participants also reported normal or corrected-to-normal vision. Young and older adults did not differ in years of education $(M=$ $14.37, S D=1.61 ; M=14.31, S D=5.04$, respectively; $t(67)=0.07, p=.944, d=.03)$ or National Adult Reading Test (NART; Nelson, 1982) full-scale IQ scores $(M=110.05, S D=4.31 ; M=$ $112.08, S D=6.74, t(67)=1.50, p=.150, d=.37)$. Scores on the short-form Geriatric Depression Scale (GDS; Yesavage \& Sheikh, 1986) were higher for young $(M=3.54, S D=2.76)$ compared with older adults $(M=1.56, S D=2.00 ; t(67)=3.41, p=.001, d=.79)$, indicating lower mood for young adults over the past week. This study was approved by the University of Western Sydney Human Research Ethics Committee (UWS HREC).

\section{Stimuli and Procedure}

Threshold assessment task. We individually determined each participant's threshold for stimulus awareness. Images of faces gazing left or right, with neutral expressions, were presented 
in a pseudo-randomized order. Participants viewed blocks of four consecutive gaze-cues, starting with a presentation time of $8.33 \mathrm{~ms}$ (equivalent to one screen refresh using a $120 \mathrm{~Hz}$ monitor). Each subsequent set of four cues was presented for an additional $8.33 \mathrm{~ms}$, up to a maximum total presentation time of $99.96 \mathrm{~ms}$. Each individual gaze-cue was immediately masked with a grey oval (see Figure 1), and participants were asked whether they perceived the cue (i.e., the face with gaze averted left or right). If so, they were asked to indicate the direction of gaze without guessing. Once the participant correctly identified a gaze direction, the corresponding presentation time was regarded as their lowest level of awareness and that presentation time minus 8.33 ms was used as their gaze-cue presentation time in the subliminal gaze-cuing task. The mean subliminal gaze-cue presentation times were $18.08 \mathrm{~ms}(S D=11.33)$ for young and $40.40 \mathrm{~ms}(S D=17.08)$ for older participants. These presentation times for subliminal stimuli are consistent with past research (e.g., Bailey \& Henry, 2009; Lee \& Knight, 2009).

Gaze-cuing task. Gaze-cues were 21 x $26 \mathrm{~cm}$ images of 10 young and 10 older faces (5 male, 5 female) taken from the CAL/PAL Face Database (Minear \& Park, 2004), and equated for neutrality of expression based on the ratings of young $(n=24)$ and older $(n=24)$ adults (Ebner, 2008). Gaze direction was manipulated to the right and left using Adobe Photoshop, and gaze was averted by 0.29 degrees of visual angle.

Following Sato et al. (2007, 2010), participants completed 160 trials in randomized order in four blocks ( 2 supraliminal, 2 subliminal) of 40 trials each (20 young, 20 older faces; 10 congruent and 10 incongruent trials for each face age group). Trials also consisted of equivalent numbers of left and right gaze-cues, and order of task type (subliminal, supraliminal) was counterbalanced across participants. All participants completed 10 practice trials before commencing each of the supraliminal and subliminal tasks, and took breaks between each block. 
As shown in Figure 1, each trial began with a $1 \times 1 \mathrm{~cm}$ central fixation cross, which remained on the screen for 1,000 ms. Participants were asked to focus on the fixation until the target appeared, and to return their gaze to the fixation after making each response. The gaze-cue then replaced the fixation cross for $200 \mathrm{~ms}$ in the supraliminal condition. This stimulus onset asynchrony (time from onset of cue to onset of target) consistently results in attention orienting in response to centrally presented cues (Hietanen \& Leppanen, 2003), including among older adults (Slessor et al., 2008). In the subliminal condition, the gaze-cue presentation time was based on the threshold assessment task, and the cue was immediately masked with a grey oval so that the total presentation time was $200 \mathrm{~ms}$. Next, the target (an asterix approximately $1 \mathrm{x} 1 \mathrm{~cm}$ ) appeared $16.5 \mathrm{~cm}$ to either the left or right of the center of the screen, and cue and target remained on screen until a response was made.

In order to assess spontaneous gaze following, participants were informed that when faces appear they will look away from the target as often as toward the target, and therefore cannot be relied on to find the target. Prior to commencing each block, participants were reminded to indicate as quickly and as accurately as possible whether the asterix/target appears on the right or left of the screen by pressing the corresponding right or left key. They were also reminded to look back at the fixation cross in the center of the screen after each decision.

The tasks were run using DMDX programming software (Version 4.0.6.0). Stimuli were presented on a Samsung 26-inch LCD monitor with a refresh rate of $120 \mathrm{~Hz}$ and a resolution of 1,440 x 900 pixels. At the completion of the subliminal task participants were asked whether they perceived any of the gaze-cues and they all reported that they did not.

Data Reduction. In each task, error frequency was less than 3\%. Therefore, to avoid ceiling effects, and consistent with previous research assessing gaze following in aging (Petrican 
et al., 2013; Slessor et al., 2008; 2010), reaction times (RTs) to congruent and incongruent trials were the main dependent variables. We removed all RTs greater than $8 \mathrm{~s}(<.01 \%$ of the data in each age group) because they indicate that a participant may have been distracted (see Lee \& Knight, 2009). Then, following Slessor et al. (2008, 2010), we removed all RTs less than $100 \mathrm{~ms}$ (too quick to indicate meaningful responding; also $<.01 \%$ of data), then calculated median RTs individually for each participant, and subsequently transformed these data to reciprocals to control for positive skew and normalize the data. Lastly, four young and three older participants who had at least one gaze-cuing effect more than 2.5 SDs from their group mean were removed from analyses.

\section{Results}

The descriptive statistics for young and older participants' raw median RT performance on each of the gaze-cuing tasks are presented in Table 1. To assess potential age differences in gaze-cuing, we conducted a $2 \times 2 \times 2 \times 2$ mixed-design analysis of variance (ANOVA) with reciprocal RTs as the dependent variable, using SPSS version 21. The between-subjects factor was participant age group (young, older), and within-subjects factors were task (supraliminal, subliminal), congruity (congruent, incongruent), and face age (young, older). This revealed main effects of participant age group, $F(1,60)=51.10, p<.001, \eta_{\mathrm{p}}^{2}=.46$, congruity, $F(1,60)=53.72, p<.001, \eta_{\mathrm{p}}{ }^{2}=.47$, and face age, $F(1,60)=22.07, p<.001, \eta_{\mathrm{p}}{ }^{2}=.27$, but not task, $F(1,60)=1.45, p=.234, \eta_{\mathrm{p}}^{2}=.02$. There was a congruity $\mathrm{x}$ participant age group interaction, $F(1,60)=5.41, p=.023, \eta_{\mathrm{p}}{ }^{2}=.08$, as well as task x congruity, $F(1,60)=9.35$, $p=.003, \eta_{\mathrm{p}}{ }^{2}=.14$, face age $\mathrm{x}$ congruity, $F(1,60)=7.76, p=.007, \eta_{\mathrm{p}}{ }^{2}=.12$, and task $\mathrm{x}$ face age, $F(1,60)=17.63, p<.001, \eta_{\mathrm{p}}{ }^{2}=.23$, interactions. The latter three interactions were qualified by a three-way task $\mathrm{x}$ face age $\mathrm{x}$ congruity interaction, $F(1,60)=13.74, p<.001, \eta_{\mathrm{p}}{ }^{2}=.19$. All 
other two-, three-, and four-way interactions were not significant, all $F \mathrm{~s}(1,60) \leq 3.86, p \mathrm{~s} \geq .054$, $\eta_{\mathrm{p}}^{2} \leq .06$

Follow-up tests for the congruity $\mathrm{x}$ participant age group interaction revealed simple main effects of congruity for both young, $F(1,60)=46.60, p<.001, \eta_{\mathrm{p}}{ }^{2}=.44$, and older participants, $F(1,60)=12.52, p=.001, \eta_{\mathrm{p}}{ }^{2}=.17$. One-sample $t$-tests showed that the gaze cuing effects (i.e., reciprocal RTs on incongruent trials minus reciprocal RTs on congruent trials, averaged across type of task and face age) were greater than chance for both young, $t(30)=6.66, p<.001$, and older participants, $t(30)=3.63, p=.001$. However, an independent samples $t$-test showed that the strength of the congruity effect was significantly smaller for older than for young participants, $t(60)=2.33, p=.023, d=.60($ see Figure 2$)$.

To follow-up the task $\mathrm{x}$ face age $\mathrm{x}$ congruity interaction, we conducted $2 \times 2$ ANOVAs separately for the supraliminal and subliminal tasks, with the within-subjects factors of congruity and face age. For the supraliminal task, this revealed a main effect of congruity, $F(1,61)=9.44$, $p=.003, \eta_{\mathrm{p}}{ }^{2}=.13$, but not face age, $F(1,61)=1.44, p=.234, \eta_{\mathrm{p}}{ }^{2}=.02$, and no congruity $\mathrm{x}$ face age interaction, $F(1,61)=.31, p=.578, \eta_{\mathrm{p}}{ }^{2}<.01$. For the subliminal task, there were main effects of congruity, $F(1,61)=45.66, p<.001, \eta_{\mathrm{p}}{ }^{2}=.43$, and face age, $F(1,61)=32.62$, $p<.001, \eta_{\mathrm{p}}{ }^{2}=.35$, as well as a congruity $\mathrm{x}$ face age interaction, $F(1,61)=21.98, p<.001$, $\eta_{\mathrm{p}}^{2}=.27$

Follow-up tests for the congruity $\mathrm{x}$ face age interaction in the subliminal task revealed a simple main effect of face age for congruent, $F(1,60)=43.31, p<.001, \eta_{\mathrm{p}}{ }^{2}=.42$, but not incongruent trials, $F(1,60)=1.92, p=.171, \eta_{\mathrm{p}}{ }^{2}=.03$, indicating that, averaged across participant age group, responding was faster to older relative to young faces in the congruent, but not the incongruent, condition. Thus, although one-sample $t$-tests showed that the congruity 
effect was above chance in response to older, $t(61)=7.59, p<.001$, and younger faces, $t(61)=$ $2.43, p=.018$, it was greater in response to the older faces (see Figure 3).

\section{Discussion}

In Study 1, consistent with our prediction, both young and older participants responded faster to congruent relative to incongruent gaze-cues across both types of task (supraliminal and subliminal), with this congruity effect reduced among older relative to younger participants in the supraliminal task (see Slessor et al., 2008, 2010). Yet, contrary with this prediction, subliminal cues did not attenuate older adults' overall difficulty achieving joint attention. We also found that both young and older participants responded more quickly to older relative to young faces in the subliminal task. Thus, although face age did not influence gaze-cuing in the supraliminal task, both young and older adults followed the gaze of subliminal faces more readily when they were older rather than young. Thus, our findings were not consistent with Slessor et al.'s (2010) finding that only young participants demonstrate own-age biases in gaze following, and were only partly in line with the own-age bias demonstrated by both young and older adults in face recognition (Rhodes \& Anastasi, 2012).

The data suggest that older adults may benefit from a reduction in demands for conscious, deliberative processing when achieving joint attention with own-age faces that potentially represent more desirable interaction partners (Ebner et al., 2013; Wright et al., 2008). This subconscious own-age bias among older adults is also consistent with research showing that older adults find task-irrelevant own-age faces more distracting than other-age faces (Ebner \& Johnson, 2010). Our finding was novel, however, in showing this bias gaze following, and at a subconscious level of processing. As noted, contrary to Slessor et al. (2010), young participants did not demonstrate any own-age biases. This inconsistency may be attributable to methodological differences. First, unlike Slessor et al., the stimuli in the current study were static 
in order to closely match the supraliminal and subliminal task conditions. Second, the supraliminal stimuli in the current study were presented for a shorter duration (200 ms as opposed to $500 \mathrm{~ms}$ in Slessor et al., 2010). This may have reduced the capacity for allocating attention and thus the motivational processes that are suggested to be involved in the own-age bias previously seen among young adults. Nevertheless, the current data are consistent with other studies showing that own-age biases may be more salient among older than young adults (Ebner et al., 2013; Wright et al., 2008; although see Rhodes \& Anastasi, 2012).

As noted, young adults behaved like older adults by following the gaze of subliminal older faces more successfully than subliminal younger faces. It is possible that both age groups subconsciously view older faces as more informative and/or trustworthy than young faces (see Johansson-Stenman, 2008). People have been shown to make rapid trustworthiness judgments within as little as $100 \mathrm{~ms}$ of viewing a face (Willis \& Todorov, 2006). Even more tellingly, the same faces are judged as less trustworthy when exposure time increases beyond $100 \mathrm{~ms}$. This potential explanation for the current data may at first appear inconsistent with Petrican et al.'s (2013) recent finding that older participants are more likely to follow the gaze of trustworthy relative to untrustworthy faces under deliberative, but not more automatic, processing conditions. However, Petrican et al. used computer-generated stimuli that displayed trustworthiness via specific facial features, rather than age. In particular, their trustworthy faces appeared subtly happy, while their untrustworthy faces appeared subtly angry. It is therefore feasible that their findings reflect conscious responses specific to the emotion-related rather than face age elements of trustworthiness.

To return to the first finding of Study 1, we found that older adults experience reduced overall gaze following compared to young even when faces are presented subliminally. Despite 
previous evidence that reduced gaze-cuing with age is not attributable to age-related declines in visual contrast sensitivity (Slessor et al., 2008), one possibility is that other aspects of reduced visual acuity may have some influence on age-related difficulty following eye gaze. Another possibility is that subliminal presentation did not help older adults because the neutral facial expressions were not arousing enough. Indeed, young and older adults attend first to emotionally arousing images, and then to neutral images (Knight et al., 2007), and are better at quickly detecting emotional compared with neutral images (Leclerc \& Kensinger, 2008).

At the subconscious level, there is evidence that fearful faces with averted gaze are biologically significant since they signal a potential threat, which results in rapid and automatic responding (Morris, Öhman, \& Dolan, 1998). Moreover, recall that older adults are as proficient as young in tasks assessing early, and therefore relatively automatic responding to threatening faces (Mather \& Knight, 2006; Ruffman et al., 2009), including when presented subliminally (Bailey \& Henry, 2009). There is further evidence for the biological significance of approaching reward (Davis \& Whalen, 2001), suggesting that older adults' attention might also be subconsciously cued by positive expressions, such as happiness. This would be consistent with studies showing that older adults can process positive information in tasks that limit voluntary control, including assessments of binocular rivalry (Bannerman, Regener, \& Sahraie, 2011), and gaze fixation during divided attention (Allard \& Isaacowitz, 2008). Such findings suggest that subliminal presentation of faces expressing emotion, particularly fear and happiness, might attenuate age-related differences in gaze cuing.

Conceptually, socioemotional selectivity theory (Carstensen, Isaacowitz, \& Charles, 1999) suggests that older adults prioritize emotionally meaningful social goals due to a perception of limited time remaining in life. This in turn has been argued to result in increased 
attention to, and memory for, positive information, and/or avoidance of negative information (for a review see Mather \& Carstensen, 2005). Although older adults' positivity can sometimes be witnessed under conditions of limited cognitive control (e.g., Allard \& Isaacowitz, 2008; Bannerman et al., 2011), it is thought mainly to reflect a consciously controlled preference (Mather \& Carstensen, 2005), and thus, would be expected to occur primarily in response to supraliminal rather than subliminal cues.

Few studies have assessed age differences in how face age and valence interact in attention. The existing data suggest that older adults give preference to own-age happy but not own-age angry faces under both explicit (Ebner et al., 2013) and more implicit (Ebner \& Johnson, 2010) processing conditions. The existing study of implicit processing relied on attentional rather than sensory unawareness, with the latter considered the more implicit and automatic form of emotion processing (Tamietto \& de Gelder, 2010). Thus, the existing implicit assessment may have allowed for the recruitment of sufficient cognitive resources to enable older adults to strategically give preference to positive over negative own-age faces. In contrast, Study 2 was the first to assess face age and valence concurrently at two differing levels of consciousness and within the same sample. In line with socioemotional selectivity theory, older adults would be expected to attend more to own-age happy faces only when perceiving them consciously. Further, consistent with Study 1, both age groups would be predicted to experience generally enhanced subconscious following of older relative to young faces.

In sum, Study 2 had four aims: (1) to examine whether age differences in gaze cuing are attenuated when arousing information is processed subconsciously, (2) to examine how socioemotional selectivity theory might help to explain older adults' conscious gaze following, (3) to examine how face age and valence interact in older adults' conscious versus subconscious 
social perception, and (4) to assess whether declines in visual acuity, and specifically near vision, contribute to older adults' difficulty following gaze-cues.

\section{Study 2}

In Study 2 we expected that fearful and happy faces presented subliminally would attenuate the overall age-related decline in gaze cuing. This is because subliminally presented faces are processed implicitly, and implicit processing of emotionally arousing information remains intact with age (e.g., Bailey \& Henry, 2009; Ruffman et al., 2009). We also expected that, for older adults, happy faces would elicit stronger gaze cuing than fearful faces in the supraliminal task, in line with socioemotional selectivity theory (Carstensen et al., 1999). A further prediction, consistent with socioemotional selectivity theory, was that older adults would experience stronger gaze cuing in response to supraliminal own-age rather than other-age happy, but not fearful, faces. In addition, consistent with Study 1, both age groups were expected to attend more to the gaze of subliminal older relative to younger faces.

\section{Method}

\section{Participants}

Participants were 35 young $(M=19.71$ years, $S D=2.81$; range 18-29) and 35 older adults $(M=71.46$ years, $S D=5.35$; range 65-91). Recruitment and exclusion criteria were the same as in Study 1, resulting in the exclusion of one older adults' data from analyses. All older participants scored above 25 on the MMSE. Young and older adults did not differ in years of education $(M=13.90, S D=1.10 ; M=13.03, S D=3.92$, respectively; $t(66)=1.24, p=.218$, $d=.31$; one young adult did not provide this information). Older adults achieved higher NART full-scale IQ scores $(M=121.24, S D=4.26)$ relative to the young adults $(M=114.39, S D=$ $4.30, t(67)=6.64, p<.001, d=1.62)$. Scores on the short-form GDS were higher for young $(M$ 
$=3.66, S D=3.27)$ than older adults $(M=1.74, S D=2.19 ; t(67)=2.86, p=.006, d=.70)$, indicating lower mood for young adults over the past week. However, ratings of current mood from 1 (Not at all happy) to 7 (Very happy) did not differ for young $(M=5.20, S D=1.02)$ and older adults $(M=5.50, S D=1.02 ; t(67)=1.22, p=.227, d=.30)$. Visual acuity was assessed with the Sloan Letter Near Vision Card. Participants were required to read aloud 55 individual letters (indicative of 20/20 vision) and the number of errors (including letters not read, and averaged across separate readings from the right and left eyes) was recorded. On average, the older adults made more errors $(M=11.22, S D=4.90)$ than their younger counterparts $(M=2.73$, $S D=3.99 ; t(67)=7.90, p<.001, d=1.93)$, indicating an age-related decline in visual acuity. This study was approved by UWS HREC.

\section{Stimuli and Procedure}

Threshold assessment task. This process was the same as described in Study 1. The mean subliminal target presentation times for Study 2 were $18.33 \mathrm{~ms}(S D=11.00)$ for young and $50.73 \mathrm{~ms}(S D=20.99)$ for older participants.

Gaze-cuing task. Gaze-cues were 21 x $26 \mathrm{~cm}$ images of 16 young and 16 older faces taken from the FACES database (Ebner, Riediger, \& Lindenberger, 2008). Each group of young and older faces was made up of eight individuals expressing happiness ( 4 male, 4 female) and another eight separate individuals expressing fear (4 male, 4 female). Gaze direction was manipulated as described in Study 1.

Participants completed a total of 512 trials, with 256 trials of each task type (supraliminal, subliminal), divided into four blocks of 64 randomized trials each (16 young, 16 older faces; 8 congruent, 8 incongruent trials for each face cue age group). Trials consisted of equal numbers of left and right gaze-cues, and happy and fearful faces. Order of task type 
(subliminal, supraliminal) was counterbalanced across participants, and 10 practice trials were completed before commencing each of the supraliminal and subliminal tasks. All participants took breaks between each block to limit the influence of fatigue.

The apparatus, participant instructions, and sequencing of each trial (see Figure 1) were the same as in Study 1. All participants reported at the completion of testing that they did not perceive the subliminal gaze-cues.

Emotion ratings. At the conclusion of testing, participants rated the intensity of expression in the 16 young and 16 older faces ( 8 happy and 8 fearful in each face age group) from the gaze-cuing tasks they completed. The faces were presented individually, in a randomized order, and participants were asked to rate how 'scared' or 'happy' (depending on the emotion expressed by that face) the person looks on a scale from 1 (Not at all) to 7 (Very).

Data Reduction. We used the same process as in Study 1. This resulted in the removal of less than $.01 \%$ of the data with RTs greater than $8 \mathrm{~s}$ or less than $100 \mathrm{~ms}$ in each age group, as well as exclusion of two young and five older adults. One additional young adult was excluded for apparently not understanding the instructions (always responding to the direction of the gazecue rather than the direction of the target). Error rates remained low at less than $3 \%$ of trials for each task.

\section{Results}

Gaze-cuing task. The descriptive statistics for young and older participants' performance on each of the gaze-cuing tasks are presented in Table 2 . To investigate potential age differences in gaze-cuing we conducted a $2 \times 2 \times 2 \times 2 \times 2$ mixed-design ANOVA, using SPSS version 21. The between-subjects factor was participant age group (young, older), and within-subjects factors were task (supraliminal, subliminal), congruity (congruent, incongruent), face age 
(young, older), and emotion (happy, fearful). The dependent variable was reciprocal RT. This revealed main effects of participant age group, $F(1,59)=64.58, p<.001, \eta_{\mathrm{p}}{ }^{2}=.52$, and congruity, $F(1,59)=103.51, p<.001, \eta_{\mathrm{p}}{ }^{2}=.64$, but not task, face age, or emotion, all $F \mathrm{~s}(1,59) \leq .54, p \mathrm{~s} \geq .465, \eta_{\mathrm{p}}{ }^{2}<.01$. There were, however, participant age group x congruity, $F(1,59)=6.58, p=.013, \eta_{\mathrm{p}}{ }^{2}=.10$, and task $\mathrm{x}$ congruity interactions, $F(1,59)=11.14, p=.001$, $\eta_{\mathrm{p}}{ }^{2}=.16$, that were qualified by a three-way participant age group $\mathrm{x}$ task $\mathrm{x}$ congruity interaction, $F(1,59)=7.09, p=.010, \eta_{\mathrm{p}}{ }^{2}=.11$. There were also face age $\mathrm{x}$ emotion, $F(1,59)=6.49$, $p=.013, \eta_{\mathrm{p}}{ }^{2}=.10$, congruity $\mathrm{x}$ face age $\mathrm{x}$ emotion, $F(1,59)=6.30, p=.015, \eta_{\mathrm{p}}{ }^{2}=.10$, and participant age group $\mathrm{x}$ congruity $\mathrm{x}$ emotion interactions, $F(1,59)=13.45, p=.001, \eta_{\mathrm{p}}{ }^{2}=.19$. All other three- and four-way interactions were not significant, all $F \mathrm{~s}(1,59) \leq 2.31, p \mathrm{~s} \geq .134$, $\eta_{\mathrm{p}}^{2} \leq .04$

To follow-up the participant age group x task x congruity interaction, we analyzed reciprocal RTs, averaged across age and emotion of gaze-cue faces, with separate $2 \times 2$ ANOVAs for the supraliminal and subliminal conditions. The between-subjects factor was participant age group, and the within-subjects factor was congruity.

For the supraliminal task, this revealed main effects of participant age group, $F(1,59)=48.39, p<.001, \eta_{\mathrm{p}}{ }^{2}=.45$, and congruity, $F(1,59)=91.97, p<.001, \eta_{\mathrm{p}}{ }^{2}=.61$. There was also a participant age group $\mathrm{x}$ congruity interaction, $F(1,59)=12.94, p=.001, \eta_{\mathrm{p}}{ }^{2}=.18$. Tests to follow-up this interaction showed simple main effects of congruity for both young, $F(1,59)=91.44, p<.001, \eta_{\mathrm{p}}{ }^{2}=.61$, and older participants, $F(1,59)=17.12, p<.001, \eta_{\mathrm{p}}{ }^{2}=.23$. Importantly, one-sample $t$-tests showed that these gaze-congruity effects were above chance for both young, $t(31)=8.04, p<.001$, and older participants, $t(28)=5.62, p<.001$. However, an independent samples $t$-test showed that the strength of the supraliminal gaze congruity effect 
(i.e., reciprocal RT on incongruent trials minus reciprocal RT on congruent trials, averaged across age and emotion of gaze-cue face) was smaller for older relative to young participants (as in Experiment 1), $t(59)=3.60, p<.001, d=.94$ (see Figure 4A). We also conducted an analysis of covariance, controlling for scores on the Sloan Letter Near Vision test. This revealed no effect of visual acuity, $F(1,58)=.03, p=.876, \eta_{\mathrm{p}}{ }^{2}<.001$, and the effect of participant age group remained significant even after controlling for visual acuity, $F(1,58)=5.74, p=.020, \eta_{\mathrm{p}}{ }^{2}=.09$.

For the subliminal task, there were main effects of participant age group, $F(1,59)=75.12, p<.001, \eta_{\mathrm{p}}{ }^{2}=.56$, and congruity, $F(1,59)=30.64, p<.001, \eta_{\mathrm{p}}{ }^{2}=.34$. There was no participant age group $\mathrm{x}$ congruity interaction, $F(1,59)=.02, p=.876, \eta_{\mathrm{p}}{ }^{2}<.01$ ( $\mathrm{see}$ Figure 4A). A one-sample $t$-test showed that this gaze-congruity effect indicated greater than chance performance, $t(60)=5.60, p<.001$.

Following-up the participant age group x congruity $\mathrm{x}$ emotion interaction, we analyzed reciprocal RTs averaged across task type and face age with separate 2 x 2 ANOVAs for young and older participants. The within-subjects factors were emotion and congruity.

For young participants, there was a main effect of congruity, $F(1,31)=73.45, p<.001$, $\eta_{\mathrm{p}}{ }^{2}=.70$, but not emotion, $F(1,31)=.02, p=.901, \eta_{\mathrm{p}}{ }^{2}<.01$. However, there was a congruity $\mathrm{x}$ emotion interaction, $F(1,31)=4.33, p=.046, \eta_{\mathrm{p}}{ }^{2}=.12$. Tests to follow-up the interaction revealed simple main effects of congruity for both happy, $F(1,31)=62.58, p<.001, \eta_{\mathrm{p}}{ }^{2}=.67$, and fearful faces, $F(1,31)=30.00, p<.001, \eta_{\mathrm{p}}{ }^{2}=.49$. One-sample $t$-tests showed that young participants' gaze congruity effects (i.e., reciprocal RTs to incongruent gaze-cues minus reciprocal RTs to congruent gaze-cues, averaged across type of task and face age) were above chance for both happy, $t(31)=7.91, p<.001$, and fearful faces, $t(31)=5.48, p<.001$. However, 
a paired-samples $t$-test showed that the congruity effect was stronger for happy than fearful faces, $t(31)=2.08, p=.046, d=.75$ (see Figure 4B).

For older participants, there was a main effect of congruity, $F(1,28)=33.61, p<.001$, $\eta_{\mathrm{p}}{ }^{2}=.55$, but not emotion, $F(1,28)=1.06, p=.311, \eta_{\mathrm{p}}{ }^{2}=.04$. However, there was a congruity $\mathrm{x}$ emotion interaction, $F(1,28)=14.63, p=.001, \eta_{\mathrm{p}}{ }^{2}=.34$. Tests to follow-up the interaction revealed simple main effects of congruity for both happy, $F(1,28)=11.61, p=.002, \eta_{\mathrm{p}}{ }^{2}=.29$, and fearful faces, $F(1,28)=44.23, p<.001, \eta_{\mathrm{p}}{ }^{2}=.61$. One-sample $t$-tests showed that older participants' gaze congruity effects (i.e., reciprocal RTs to incongruent gaze-cues minus reciprocal RTs to congruent gaze-cues, averaged across type of task and face age) were above chance for both happy, $t(28)=3.41, p=.002$, and fearful faces, $t(28)=6.65, p<.001$. However, a paired-samples $t$-test showed that the congruity effect was stronger for fearful than happy faces, $t(28)=3.83, p=.002, d=1.45$ (see Figure 4B).

To follow-up the congruity $\mathrm{x}$ face age $\mathrm{x}$ emotion interaction we analyzed reciprocal RTs, averaged across task type and participant age group, with separate 2 × 2 ANOVAs for happy and fearful faces. The within-subjects factors were face age and congruity.

For fearful faces, there was a main effect of congruity, $F(1,60)=71.27, p<.001$, $\eta_{\mathrm{p}}{ }^{2}=.54$, but not face age, $F(1,60)=2.08, p=.154, \eta_{\mathrm{p}}{ }^{2}=.03$, and there was no congruity $\mathrm{x}$ face age interaction, $F(1,60)=1.15, p=.287, \eta_{\mathrm{p}}^{2}=.02$.

For happy faces, there were main effects of face age, $F(1,60)=6.08, p=.017, \eta_{\mathrm{p}}{ }^{2}=.09$, and congruity, $F(1,60)=55.81, p<.001, \eta_{\mathrm{p}}{ }^{2}=.48$, as well as a face age $\mathrm{x}$ congruity interaction, $F(1,60)=4.52, p=.038, \eta_{\mathrm{p}}{ }^{2}=.07$. Tests to follow-up this interaction revealed simple main effects of congruity for young, $F(1,60)=17.70, p<.001, \eta_{\mathrm{p}}{ }^{2}=.23$, and older faces, $F(1,60)=$ $42.65, p<.001, \eta_{\mathrm{p}}{ }^{2}=.42$. One-sample $t$-tests showed that the gazing cuing effects in response to 
happy expressions were above chance for both young, $t(60)=4.21, p<.001$, and older faces, $t(60)=6.53, p<.001$. However, a further paired-samples $t$-test showed that this effect was larger for older than younger faces, $t(60)=2.13, p=.038, d=.55$ (see Figure 4C).

Emotion ratings. To ensure age-related differences in the gaze-cuing tasks were not influenced by differences in perceived strength of emotion for each type of face, we conducted a $2 \times 2 \times 2$ ANOVA on emotion intensity ratings. The between-subjects factor was participant age group (young, older), and the within-subjects factors were face age (young, older), and emotion (happy, fearful). There was no main effect of participant age group, $F(1,59)=1.33, p=.253$, $\eta_{\mathrm{p}}^{2}=.02$, or face age, $F(1,59)=2.36, p=.130, \eta_{\mathrm{p}}{ }^{2}=.04$. However, there was a main effect of face emotion, $F(1,59)=63.88, p<.001, \eta_{\mathrm{p}}{ }^{2}=.53$, reflecting higher ratings of emotional intensity for happy relative to fearful facial expressions (see Table 3). There were no two- or three-way interactions, all $F \mathrm{~s}(1,59) \leq .74, p \mathrm{~s} \geq .395, \eta_{\mathrm{p}}{ }^{2} \leq .01$.

\section{Discussion}

Consistent with Study 1 and Slessor et al. (2008), Study 2 found that both young and older adults responded more quickly to congruent than incongruent gaze cues across all conditions and tasks, and older adults generally had more difficulty than young following supraliminal gaze cues. Importantly, this age difference could not be attributed to impairments in near vision or perceived intensity of emotion expressed by gaze cue faces. Moreover, as predicted, there were no age group differences in gaze cuing for emotionally arousing subliminal faces. Partly in line with expectations, older adults were better at following own-age happy but not own-age fearful faces, albeit across both types of task. In addition, both age groups attended better to the gaze of subliminal (and supraliminal) older than younger faces, but only when they 
expressed happiness. Against expectations, older adults experienced enhanced target detection in response to faces expressing fear rather than happiness.

The own-age bias for happy but not fearful faces among the older participants is consistent with other studies showing an own-age bias among older adults for happy but not angry faces in the context of both explicit (Ebner et al., 2013), and implicit processing (Ebner \& Johnson, 2010). The current study extends this previous work by directly comparing processing within subjects at two distinct levels of consciousness, and by assessing this effect for the first time in the context of gaze-directed attention. The lack of an own-age bias for fearful faces is consistent with the idea that the cognitive demands required for processing negative facial expressions, particularly among older adults (Ruffman et al., 2008), may override own-age effects (Ebner et al., 2013). It might also be that the expression of fear in a face with averted gaze receives priority for attention based on the biological relevance of rapidly detecting threat (Morris, Öhman, \& Dolan, 1998) over and above social cues associated with the age of a face. A final potential interpretation is that, consistent with socioemotional selectivity theory, happy older faces may, at least in part, be preferentially attended by other older adults in order to enhance positive social experiences with preferred interaction partners.

Averaged across type of task and face age, older adults were more likely to attend to targets cued by faces expressing fear rather than happiness, whereas young adults were more likely to attend to targets cued by faces expressing happiness than fear. Interestingly, fearful faces are typically rated as more arousing than happy faces (Hansen \& Hansen, 1988), but in the present study, both young and older participants rated the happy faces as more intense, and presumably, therefore, more arousing than the fearful faces. Mather's (2007) object-based framework describes how an arousing object reduces attention to the broader scope of a scene. 
Yet, there seems no straightforward way to apply this theory to the present findings given that young and older adults both rated happy faces as more intense, yet showed opposite gaze-cuing effects. An alternative explanation for older adults' overall enhanced gaze-cuing in response to fearful faces may be that threat detection becomes more salient with age leading to prioritization of the gaze of fearful faces. Specifically, both automatic responding to threat and strategic motivation to detect threat might increase with age as physical capacity to deal with danger diminishes. This is in line with research showing that older adults are more likely than young to engage in cautious behavior aimed at ameliorating the threat of crime (Kappes, Greve, \& Hellmers, 2013; Sacco \& Nakhaie, 2001).

Study 2 was the first to show that young and older adults are equally proficient in following the gaze of emotionally arousing subliminal faces. This is consistent with studies showing that both young and older adults rapidly and automatically detect emotional information in a visual search task, regardless of valence (Leclerc \& Kensinger, 2008), as well as evidence that young and older adults demonstrate equivalent levels of spontaneous mimicry of happy and angry subliminal faces (Bailey \& Henry, 2009). The data align more specifically with studies showing that older adults do not differ from young in implicit threat detection (Mather \& Knight, 2006; Ruffman et al., 2009), and are capable of processing positive information when voluntary control is limited (Allard \& Isaacowitz, 2008; Bannerman et al., 2011). Taken together, the evolutionary drive that promotes automatic avoidance of threat and approach of reward (see Davis \& Whalen, 2001) appears to persist into older adulthood. The current data extend this automatic processing in older adults to the detection of ambiguous threats and rewards that are indirectly suggested by averted eye gaze.

\section{General Discussion}


To the best of our knowledge the current studies were the first to assess the effects of age of participant (young, older), face age (young, older), and positive versus negative emotion (happiness, fear) on subconscious gaze-directed attention. These were also the first studies to directly compare conscious versus subconscious aspects of young and older adults' gaze following. The current research therefore contributes to an enhanced understanding of dissociable age effects on conscious and subconscious aspects of social perception. In Study 1, older adults demonstrated difficulty achieving joint attention in response to both supraliminal and subliminal gaze-cue faces with neutral expressions. There was also increased subconscious following of the gaze of older relative to young faces with neutral expressions among both groups of participants. In Study 2, age-related difficulty following supraliminal gaze cues was eliminated in response to subliminal gaze cues that were emotionally arousing. Averaged across all conditions, older adults also gave preference to the gaze of faces expressing fear rather than happiness, but this did not extend to their own-age biases, which were evident in response to faces expressing happiness, but not fear.

As noted, older adults might demonstrate difficulty following the gaze of supraliminal faces because they strategically direct their attention away from the eye region of faces (Murphy \& Isaacowitz, 2010; Sullivan et al., 2007; Wong et al., 2005). This in turn suggests that gaze cuing would be preserved for older adults when responding to subliminal stimuli, which bypass the capacity for strategic control. Indeed, we found impaired conscious but intact subconscious gaze following in response to faces expressing emotion (Study 2). However, when the faces had neutral expressions (Study 1), older adults experienced reduced gaze cuing to both subliminal and supraliminal stimuli. It might be that automatic, non-strategic attention to the upper half of 
the face during gaze cuing varies as a function of the arousal level of a stimulus. Future studies should directly test this hypothesis using measures such as eye tracking.

The tendency for happy older (vs. younger) faces to enhance young and older adults' gaze-cuing may be consistent with the suggestion in Study 1 that neutral older faces are subconsciously perceived as more trustworthy than young faces. The question, then, is why this was evident across both subconscious and conscious processing in Study 2, but only the former in Study 1. Unlike in Study 1, where perceptions of trustworthiness may have rapidly become more negative with neutral faces and increased exposure time (Willis \& Todorov, 2006), the happy expressions in Study 2 may have maintained the impression of trustworthiness. The current data are therefore consistent with Petrican's (2013) finding that older adults pay more attention to the gaze of trustworthy faces that appear happy as opposed to untrustworthy faces that appear angry. Alternatively, the lack of own-age biases among the young participants across both studies may simply reflect the priority that older adults place on socially meaningful goals. Although a meta-analytic review demonstrated that both young and older age groups experience own-age biases (Rhodes \& Anastasi, 2012), this was specifically with respect to recognition memory for faces, which may differ from social perception and, more specifically, gaze cuing. Indeed, as noted, other studies have suggested that own-age biases in social perception may be more prevalent among older age groups, and the case for this argument has been strengthened by the current findings (Ebner et al., 2013; Wright et al., 2008). In practical terms, this suggests that older adults might be skilled in establishing joint attention, and thus social communication (Charman et al., 2000), with preferred interaction partners (Ebner \& Johnson, 2010; He et al., 2011; Wright et al., 2008). This is consistent with increased motivation to enhance mood and feelings of social connectedness in later life, as posited by socioemotional selectivity theory. 
Taken together, the current studies suggest that older adults' subconscious gaze following may be preserved for emotional but not neutral faces. This is consistent with LeClerc and Kensinger's (2008) finding that older adults have an advantage detecting implicit emotional over neutral information, regardless of the valence. However, our comparison of emotional and neutral faces was not within-subjects so that further exploration of the current data may be needed. It could also be argued that increased arousal, rather than happy and fearful expressions per se, contributed to intact subconscious gaze following with age. As described by Mather's (2007) object-based framework, arousal provided one potential explanation for the finding that older adults' attention was cued more successfully by fearful relative to happy faces. Future studies should systematically manipulate both valence and arousal to determine which has the greater influence over older adults' gaze-directed attention, and ultimately social perception in general.

A further potential limitation was that one of our explanations for older adults' own-age biases relied on past evidence that older adults prefer to interact with same age partners (Ebner \& Johnson, 2010; He et al., 2011; Wright et al., 2008). There may be individual differences that were not captured within the current study and as such, future research should directly assess whether participants spend more time with own or other age group members, as well as which age group they prefer to interact with and find more trustworthy. The current data might also be limited by the use of faces from different databases in the two studies. Nevertheless, the primary aim was to assess the effects of age on conscious versus subconscious social perception, rather than on responding to emotional versus neutral stimuli. Lastly, although stimuli were presented subliminally to ensure subconscious processing of gaze-cues, participants were required to consciously make explicit behavioral responses to indicate the location of each target (i.e., with a 
key press). Future studies could assess subconscious responding in gaze-directed attention by tracking eye movements to the location of the targets. This would provide a more comprehensive understanding of the extent and limits of older adults' subconscious social perceptual abilities.

In conclusion, the current research highlights the importance of testing both conscious and subconscious components of age differences in social perception. Consistent with a larger body of research in the cognitive aging literature (e.g., Craik \& Salthouse, 2000; Fleischman et al., 2004; Jennings \& Jacoby, 1993; Phillips \& Henry, 2005), there is growing evidence in the socioemotional aging literature that impairments evidenced in some aspects of conscious, controlled social perception may be relatively preserved in the context of subconscious, automatic processing. In particular, age-related difficulty in achieving joint attention via eye gaze is attenuated when interacting subconsciously with faces that are emotionally arousing, or when older faces with neutral expressions or expressing happiness maximize the personal social relevance for older adults. 


\section{References}

Allard, E., \& Isaacowitz, D. (2008). Are Preferences in Emotional Processing Affected by Distraction? Examining the Age-Related Positivity Effect in Visual Fixation within a Dual-Task Paradigm. Aging Neuropsychology and Cognition, 15(6), 725-743. doi: $10.1080 / 13825580802348562$

Bailey, P. E., \& Henry, J. D. (2008). Growing less empathic with age: Disinhibition of the selfperspective. Journals of Gerontology Series B-Psychological Sciences and Social Sciences, 63(4), P219-P226.

Bailey, P. E., Henry, J. D., \& Nangle, M. R. (2009). Electromyographic Evidence for AgeRelated Differences in the Mimicry of Anger. Psychology and Aging, 24(1), 224-229. doi: $10.1037 / \mathrm{a} 0014112$

Bannerman, R. L., Regener, P., \& Sahraie, A. (2011). Binocular Rivalry: A Window Into Emotional Processing in Aging. Psychology and Aging, 26(2), 372-380. doi: $10.1037 / \mathrm{a} 0022029$

Carstensen, L. L., Isaacowitz, D. M., \& Charles, S. T. (1999). Taking time seriously - A theory of socioemotional selectivity. American Psychologist, 54(3), 165-181. doi: 10.1037//0003-066x.54.3.165

Charman, T., Baron-Cohen, S., Swettenham, J., Baird, G., Cox, A., \& Drew, A. (2000). Testing joint attention, imitation, and play as infancy precursors to language and theory of mind. Cognitive Development, 15(4), 481-498. doi: 10.1016/s0885-2014(01)00037-5

Cohn, N. B., Dustman, R. E., \& Bradford, D. C. (1984). Age-related decrements in Stroop Colour Test performance. Journal of Clinical Psychology, 40, 1244-1250. doi: 10.1002/1097-4679(198409)40:5<1244::AID-JCLP2270400521>3.0.CO;2-D 
Craik, F. I. M., \& Salthouse, T. A. (2000). Handbook and Aging and Cognition (2nd ed.). Mahwah, NJ: Erlbaum.

Davis, M., \& Whalen, P. J. (2001). The amygdala: vigilance and emotion. Molecular Psychiatry, 6(1), 13-34. doi: 10.1038/sj.mp.4000812

Deaner, R. O., Shepherd, S. V., \& Platt, M. L. (2007). Familiarity accentuates gaze cuing in women but not men. Biology Letters, 3(1), 64-67. doi: 10.1098/rsbl.2006.0564

Driver, J., Davis, G., Ricciardelli, P., Kidd, P., Maxwell, E., \& Baron-Cohen, S. (1999). Gaze perception triggers reflexive visuospatial orienting. Visual Cognition, 6(5), 509-540. doi: $10.1080 / 135062899394920$

Ebner, N. C. (2008). Age of face matters: Age-group differences in ratings of young and old faces. Behavior Research Methods, 40(1), 130-136. doi: 10.3758/brm.40.1.130

Ebner, N. C., He, Y., \& Johnson, M. K. (2011). Age and emotion affect how we look at a face: Visual scan patterns differ for own-age versus other-age emotional faces. Cognition and Emotion, 25(6), 983-997. doi: 10.1080/02699931.2010.540817

Ebner, N. C., \& Johnson, M. K. (2010). Age-group differences in interference from young and older emotional faces. Cognition and Emotion, 24(7), 1095-1116. doi: $10.1080 / 02699930903128395$

Ebner, N. C., Johnson, M. R., Rieckmann, A., Durbin, K. A., Johnson, M. K., \& Fischer, H. (2013). Processing own-age vs. other-age faces: Neuro-behavioral correlates and effects of emotion. Neuroimage, 78, 363-371. doi: 10.1016/j.neuroimage.2013.04.029

Ebner, N. C., Riediger, M., \& Lindenberger, U. (2008). Faces: A database of emotional facial expressions in young, middle-aged and older women and men. International Journal of Psychology, 43(3-4), 783-783. 
Fleischman, D. A., Wilson, R. S., Gabrieli, J. D. E., Bienias, J. L., \& Bennett, D. A. (2004). A longitudinal study of implicit and explicit memory in old persons. Psychology and Aging, 19, 617-625. doi: 10.1037/0882-7974.19.4.617

Folstein, M. F., Folstein, S. E., \& McHugh, P. R. (1975). Mini-mental state: A practical method for grading cognitive state of patients for the clinician. Journal of Psychiatry Research, $12,189-198$.

Hansen, R. D., \& Hansen, C. H. (1988). Repression of emotionally tagged memories - the architecture of less complex emotions. Journal of Personality and Social Psychology, 55(5), 811-818. doi: 10.1037//0022-3514.55.5.811

He, Y., Ebner, N. C., \& Johnson, M. K. (2011). What predicts the own-age bias in face recognition memory? Social Cognition, 29(1), 97-109. doi: 10.1521/soco.2011.29.1.97

Henry, J. D., Phillips, L. H., Ruffman, T., \& Bailey, P. E. (2013). A Meta-Analytic Review of Age Differences in Theory of Mind. Psychology and Aging, 28(3), 826-839. doi: $10.1037 / \mathrm{a} 0030677$

Hietanen, J. K., \& Leppanen, J. M. (2003). Does facial expression affect attention orienting by gaze direction cues? Journal of Experimental Psychology-Human Perception and Performance, 29(6), 1228-1243. doi: 10.1037/0096-1523.29.6.1228

Jennings, J. M., \& Jacoby, L. L. (1993a). Automatic versus intentional uses of memory - Aging, attention, and control. Psychology and Aging, 8(2), 283-293. doi: 10.1037/08827974.8.2.283

Johansson-Stenman, O. (2008). Who are the trustworthy, we think? Journal of Economic Behavior \& Organization, 68(3-4), 456-465. doi: 10.1016/j.jebo.2008.08.004 
Kane, M. J., Hasher, L., Stoltzfus, E. R., Zacks, R. T., \& Connelly, S. L. (1994). Inhibitory attentional mechanisms and aging. Psychology and Aging, 9(1), 103-112. doi: 10.1037/0882-7974.9.1.103

Kappes, C., Greve, W., \& Hellmers, S. (2013). Fear of crime in old age: precautious behaviour and its relation to situational fear. European Journal of Ageing, 10(2), 111-125. doi: $10.1007 / \mathrm{s} 10433-012-0255-3$

Knight, M., Seymour, T. L., Gaunt, J. T., Baker, C., Nesmith, K., \& Mather, M. (2007). Aging and goal-directed emotional attention: Distraction reverses emotional biases. Emotion, 7(4), 705-714. doi: 10.1037/1528-3542.7.4.705

Langton, S. R. H., \& Bruce, V. (1999). Reflexive visual orienting in response to the social attention of others. Visual Cognition, 6(5), 541-567. doi: 10.1080/135062899394939

Leclerc, C. M., \& Kensinger, E. A. (2008). Effects of age on detection of emotional information. Psychology and Aging, 23(1), 209-215. doi: 10.1037/0882-7974.23.1.209

Lee, L. O., \& Knight, B. G. (2009). Attentional Bias for Threat in Older Adults: Moderation of the Positivity Bias by Trait Anxiety and Stimulus Modality. Psychology and Aging, 24(3), 741-747. doi: 10.1037/a0016409

Liuzza, M. T., Cazzato, V., Vecchione, M., Crostella, F., Caprara, G. V., \& Aglioti, S. M. (2011). Follow My Eyes: The Gaze of Politicians Reflexively Captures the Gaze of Ingroup Voters. Plos One, 6(9). doi: e2511710.1371/journal.pone.0025117

Mather, M. (2007). Emotional Arousal and Memory Binding An Object-Based Framework. Perspectives on Psychological Science, 2(1), 33-52. doi: 10.1111/j.17456916.2007.00028.x 
Mather, M., \& Carstensen, L. L. (2005). Aging and motivated cognition: the positivity effect in attention and memory. Trends in Cognitive Sciences, 9(10), 496-502. doi: 10.1016/j.tics.2005.08.005

Mather, M., \& Knight, M. (2006). Angry faces get noticed quickly: Threat detection is not impaired among older adults. Journal of Gerontology: Psychological Sciences, 61, 54-57.

Minear, M., \& Park, D. C. (2004). A lifespan database of adult facial stimuli. Behavior Research Methods Instruments and Computers, 36(4), 630-633. doi: 10.3758/bf03206543

Moran, J. M. (2013). Lifespan development: The effects of typical aging on theory of mind. Behavioural Brain Research, 237, 32-40. doi: 10.1016/j.bbr.2012.09.020

Morris, J. S., Öhman, A., \& Dolan, R. J. (1998). Conscious and unconscious emotional learning in the human amygdala. Nature, 393, 467-470. doi: 10.1038/30976

Murphy, N. A., \& Isaacowitz, D. M. (2010). Age effects and gaze patterns in recognising emotional expressions: An in-depth look at gaze measures and covariates. Cognition and Emotion, 24(3), 436-452. doi: 10.1080/02699930802664623

Nelson, H. E. (1982). National Adult Reading Test (NART): Test Manual. Windsor: NFERNelson.

Okada, T., Sato, W., Kubota, Y., Usui, K., Inoue, Y., Murai, T., . . Toichi, M. (2008). Involvement of medial temporal structures in reflexive attentional shift by gaze. Social Cognitive and Affective Neuroscience, 3(1), 80-88. doi: 10.1093/scan/nsm027

Petrican, R., English, T., Gross, J. J., Grady, C., Hai, T., \& Moscovitch, M. (2013). Friend or Foe? Age Moderates Time-Course Specific Responsiveness to Trustworthiness Cues. Journals of Gerontology Series B-Psychological Sciences and Social Sciences, 68(2), 215-223. doi: 10.1093/geronb/gbs064 
Phillips, L. H., \& Henry, J. D. (2005). An evaluation of the frontal lobe theory of cognitive aging. In J. Duncan, P. McLeod \& L. H. Phillips (Eds.), Measuring the mind: Speed, control and age (pp. 191-216). Oxford: Oxford University Press

Rhodes, M. G., \& Anastasi, J. S. (2012). The own-age bias in face recognition: A meta-analytic and theoretical review. Psychology and Aging, 138(1), 146-174. doi: 10.1037/a0025750

Ristic, J., \& Kingstone, A. (2005). Taking control of reflexive social attention. Cognition, 94(3), B55-B65. doi: 10.1016/j.cognition.2004.04.005

Ruffman, T., Henry, J. D., Livingstone, V., \& Phillips, L. H. (2008). A meta-analytic review of emotion recognition and aging: Implications for neuropsychological models of aging. Neuroscience and Biobehavioral Reviews, 32, 863-881. doi:

10.1016/j.neubiorev.2008.01.001

Ruffman, T., Ng, M., \& Jenkin, T. (2009). Older Adults Respond Quickly to Angry Faces Despite Labeling Difficulty. Journals of Gerontology Series B-Psychological Sciences and Social Sciences, 64(2), 171-179. doi: 10.1093/geronb/gbn035

Sacco, V. F., \& Nakhaie, M. R. (2001). Coping with crime - An examination of elderly and nonelderly adaptations. International Journal of Law and Psychiatry, 24(2-3), 305-323. doi: 10.1016/s0160-2527(00)00074-1

Sato, W., Okada, T., \& Toichi, M. (2007). Attentional shift by gaze is triggered without awareness. Experimental Brain Research, 183(1), 87-94. doi: 10.1007/s00221-007-1025X

Sato, W., Uono, S., Okada, T., \& Toichi, M. (2010). Impairment of unconscious, but not conscious, gaze-triggered attention orienting in Asperger's disorder. Research in Autism Spectrum Disorders, 4(4), 782-786. doi: 10.1016/j.rasd.2010.02.002 
Singer, T., \& Lamm, C. (2009). The Social Neuroscience of Empathy. In M. B. Miller \& A. Kingstone (Eds.), Year in Cognitive Neuroscience 2009 (Vol. 1156, pp. 81-96)

Slessor, G., Laird, G., Phillips, L. H., Bull, R., \& Filippou, D. (2010). Age-Related Differences in Gaze Following: Does the Age of the Face Matter? Journals of Gerontology Series BPsychological Sciences and Social Sciences, 65(5), 536-541. doi: 10.1093/geronb/gbq038

Slessor, G., Phillips, L. H., \& Bull, R. (2008). Age-Related Declines in Basic Social Perception: Evidence From Tasks Assessing Eye-Gaze Processing. Psychology and Aging, 23(4), 812-822. doi: $10.1037 / \mathrm{a} 0014348$

Sullivan, S., Ruffman, T., \& Hutton, S. B. (2007). Age differences in emotion recognition skills and the visual scanning of emotion faces. Journals of Gerontology Series BPsychological Sciences and Social Sciences, 62(1), P53-P60.

Tamietto, M., \& de Gelder, B. (2010). Neural bases of the non-conscious perception of emotional signals. Nature Reviews Neuroscience, 11(10), 697-709. doi: 10.1038/nrn2889

Willis, J., \& Todorov, A. (2006). First impressions: Making up your mind after a 100-ms exposure to a face. Psychological Science, 17(7), 592-598. doi: 10.1111/j.14679280.2006.01750.x

Wong, B., Cronin-Golomb, A., \& Neargarder, S. (2005). Patterns of visual scanning as predictors of emotion identification in normal aging. Neuropsychology, 19(6), 739-749. doi: 10.1037/0894-4105.19.6.739

Wright, C. I., Negreira, A., Gold, A. L., Britton, J. C., Williams, D., \& Barrett, L. F. (2008). Neural correlates of novelty and face-age effects in young and elderly adults. Neuroimage, 42(2), 956-968. doi: 10.1016/j.neuroimage.2008.05.015 
Yesavage, J. A., \& Sheikh, J. I. (1986). 9/Geriatric Depression Scale (GDS). Clinical Gerontologist, 5(1-2), 165-173.doi: 10.1300/J018v05n01_09 


\section{Acknowledgments}

This research was supported under Australian Research Council's Discovery Projects funding scheme (project number DP130101420). Gillian Slessor was supported by a Sixth Century

Fellowship from the University of Aberdeen. We thank Marreta Coleman for research assistance. 


\section{Figure captions}

Figure 1. Stimulus sequencing and timing for supraliminal and subliminal gaze-cuing tasks. The gaze-cue face shown is of an older adult expressing fear, and is taken from the FACES database (see Study 2). Note that the faces with neutral expressions in Study 1 were taken from the CAL/PAL Face database. The presentation time of the subliminal gaze-cue (T) refers to $8.33 \mathrm{~ms}$ below each participant's individual threshold for awareness. In the supraliminal trial depicted, the target appears on the side incongruent with gaze direction, and in the subliminal trial, the target is congruent with gaze.

Figure 2. Young and older participants' gaze-congruity effects (indexed by reciprocal RT, multiplied by 100), averaged across task type and face age (Study 1). Bars represent standard errors of the between-group means.

Figure 3. Gaze congruity effects (indexed by reciprocal RT, multiplied by 100) in response to young and older faces in the subliminal versus supraliminal tasks, averaged across participant age group (Study 1). Bars represent standard errors of the within-condition means.

Figure 4. Gaze-congruity effects in Study 2 (indexed by reciprocal RT, multiplied by 100) for (A) young versus older participants, in response to supraliminal versus subliminal cues, averaged across face age and valence, (B) happy versus fearful faces, averaged across face age and type of task, and (C) young and older faces expressing happiness and fear, averaged across participant age and type of task. Bars represent standard errors of the between-group and within-condition means. 
Fig. 1

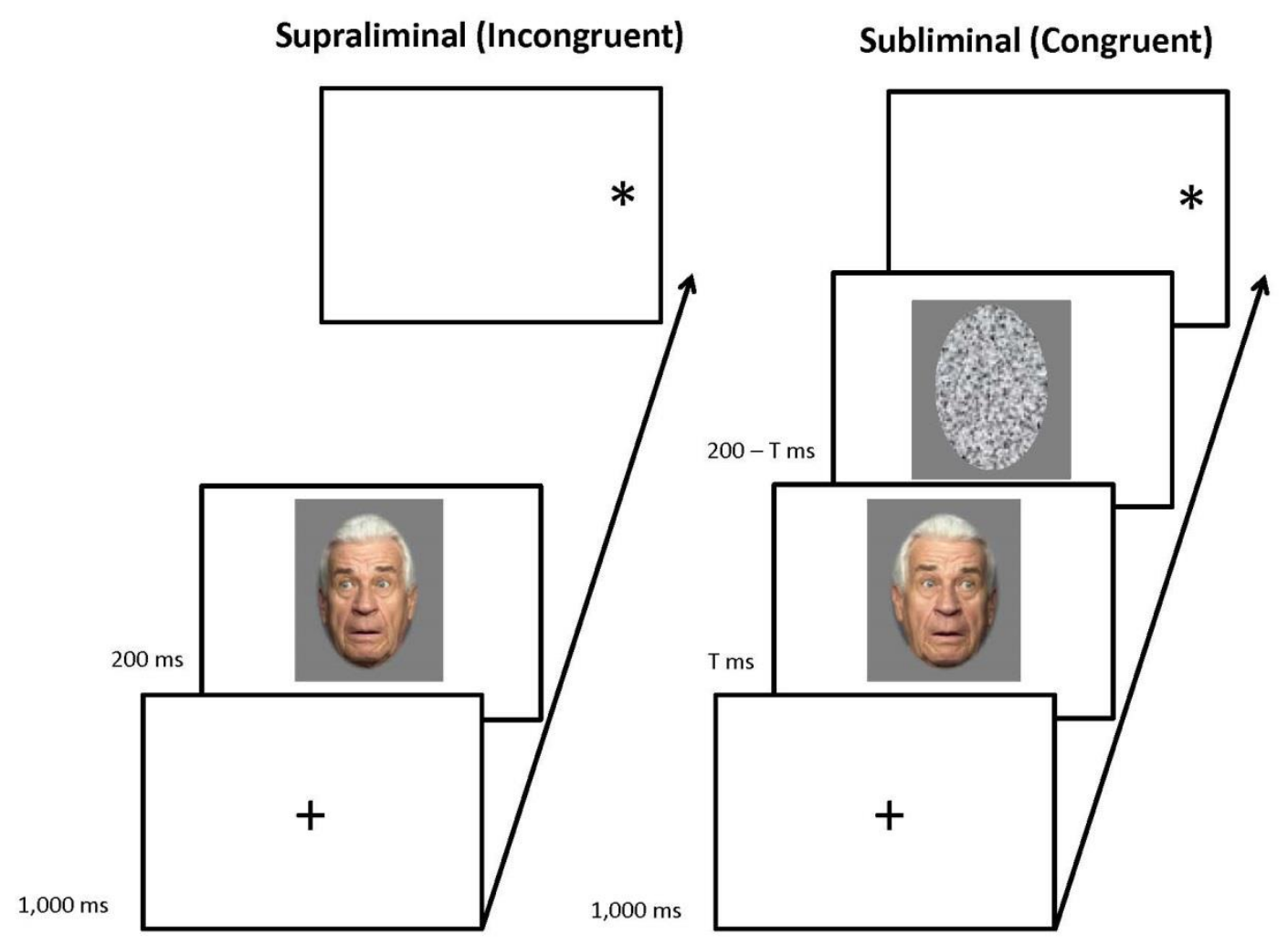


Fig. 2

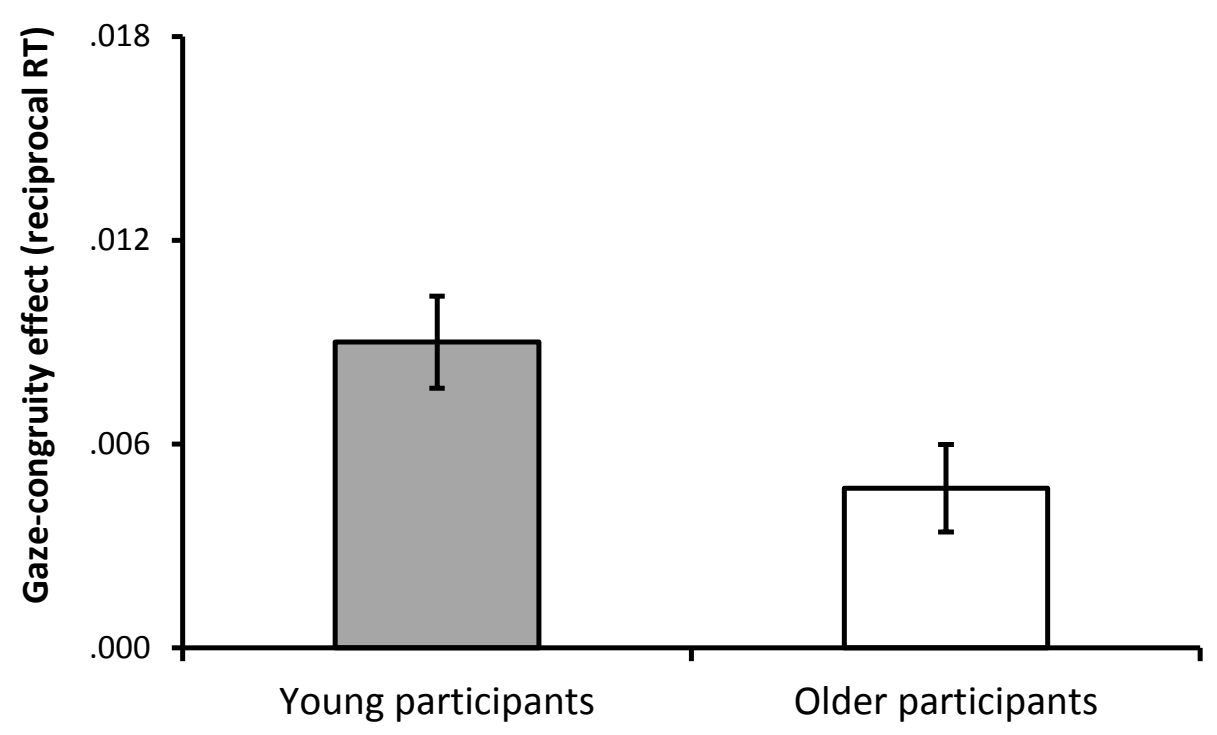


Fig. 3

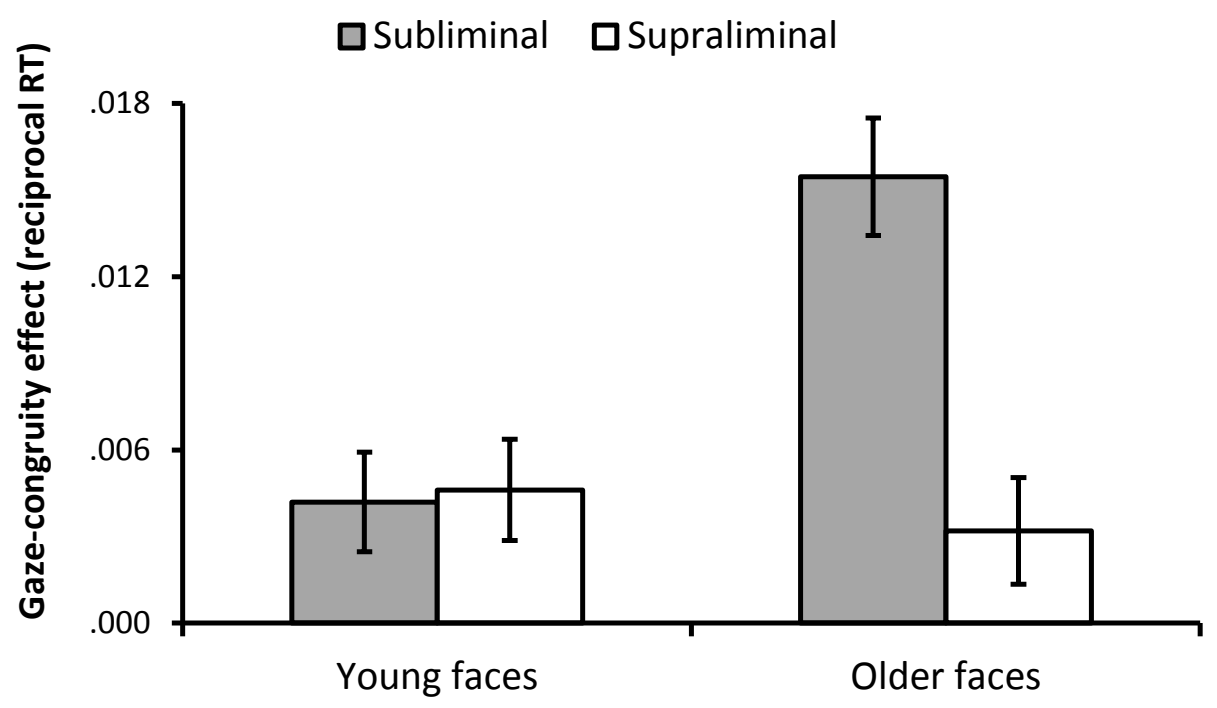


Fig. 4(A)

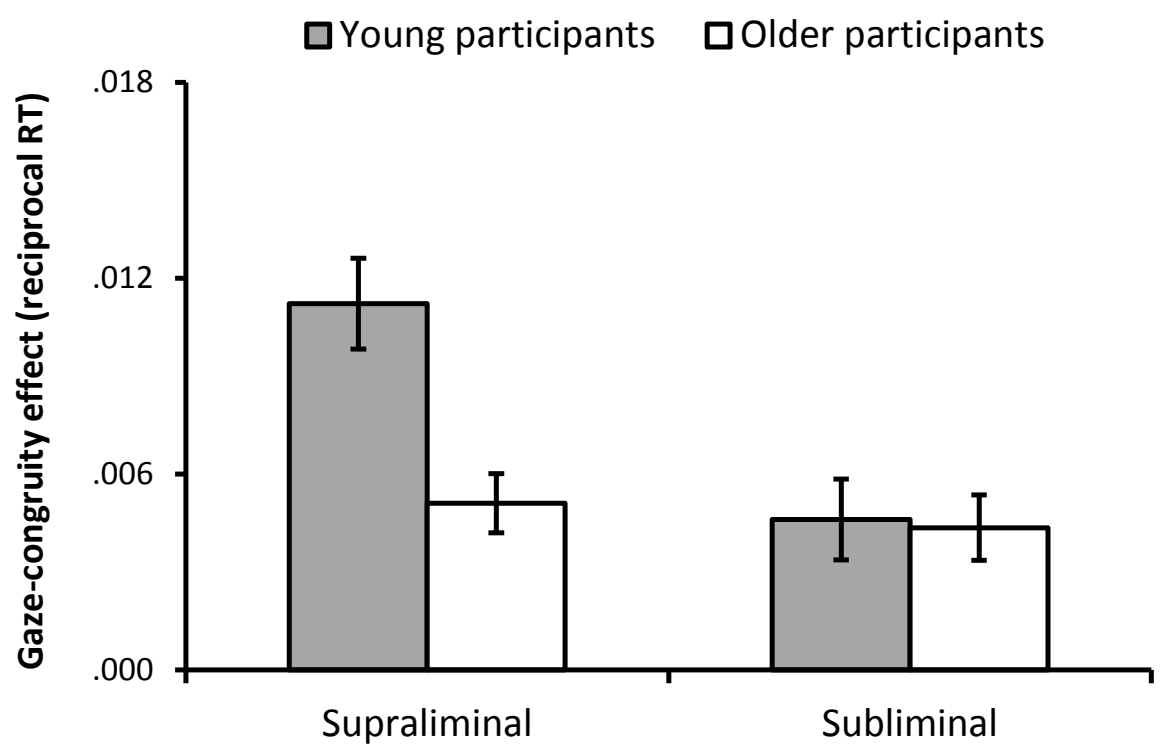


Fig. 4(B)

$\square$ Happy $\square$ Fearful

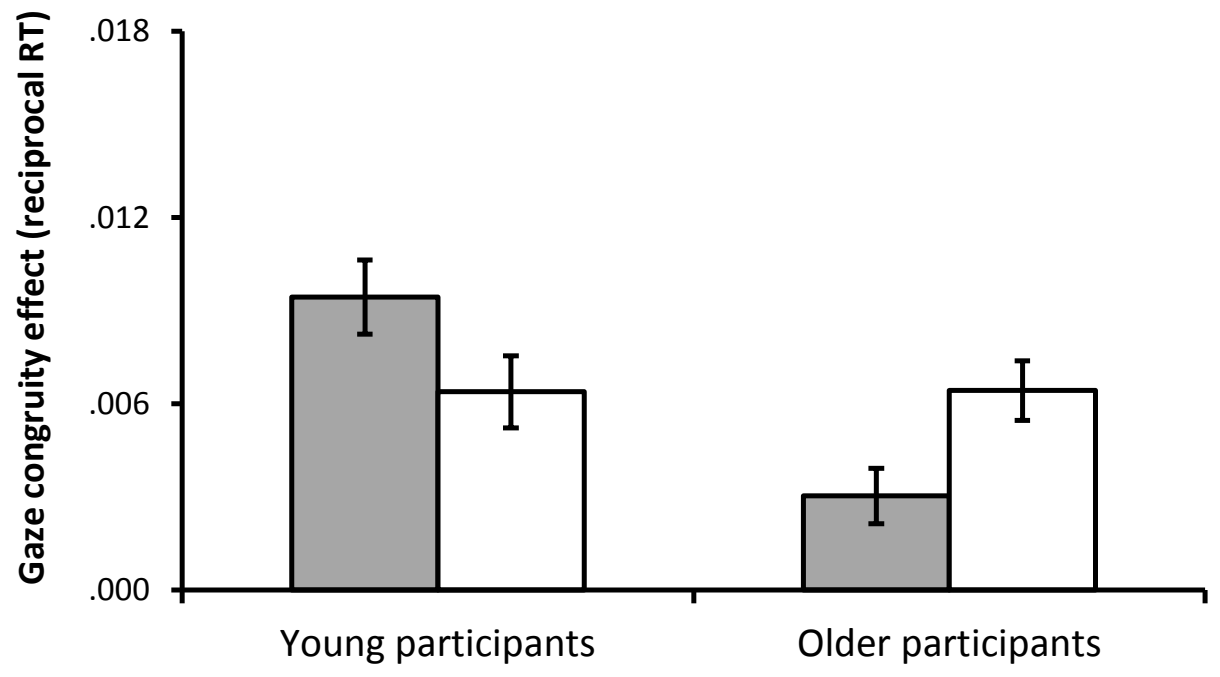


Fig. 4(C) 口Young faces $\square$ Older faces

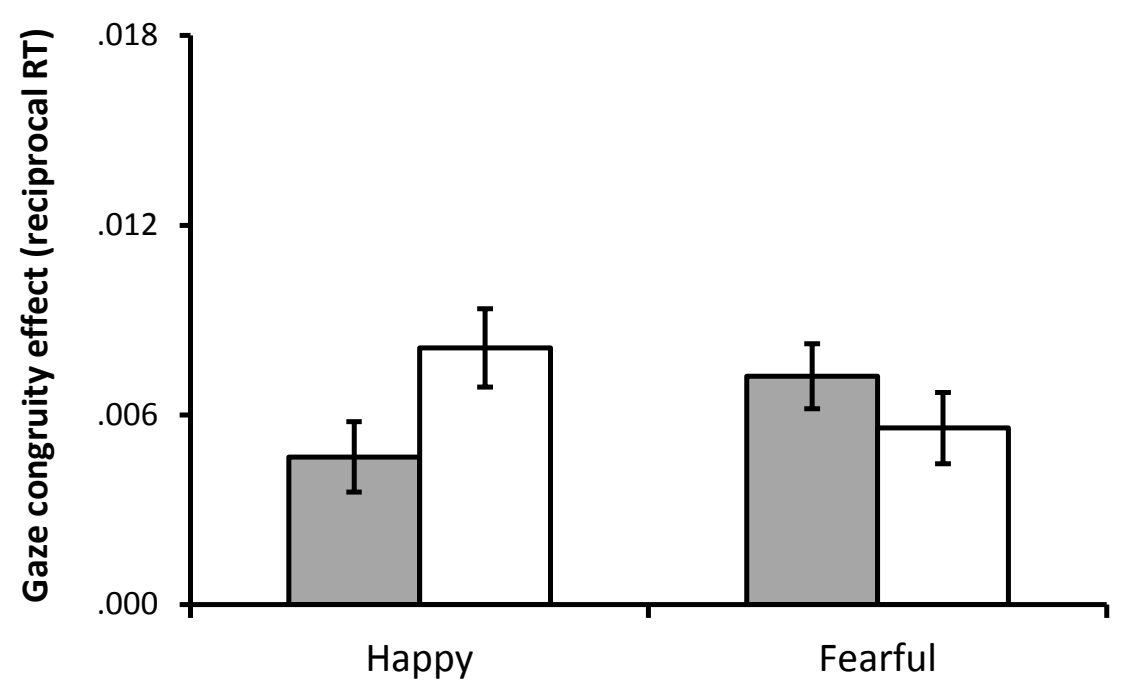


Table 1

Descriptive Statistics for Young and Older Participants' RT (ms) on Each Gaze-cuing Task in Study 1

\begin{tabular}{|c|c|c|c|c|c|c|c|c|c|}
\hline \multirow[b]{3}{*}{ Task } & \multirow[b]{3}{*}{ Face Age } & \multicolumn{4}{|c|}{ Young participants } & \multicolumn{4}{|c|}{ Older participants } \\
\hline & & \multicolumn{2}{|c|}{ Congruent } & \multicolumn{2}{|c|}{ Incongruent } & \multicolumn{2}{|c|}{ Congruent } & \multicolumn{2}{|c|}{ Incongruent } \\
\hline & & $M$ & $S D$ & $M$ & $S D$ & $M$ & $S D$ & $M$ & $S D$ \\
\hline & Young & 408.3 & 76.84 & 422.4 & 88.43 & 513.1 & 63.97 & 517.3 & 64.75 \\
\hline & Older & 410.3 & 82.44 & 416.6 & 79.74 & 521.9 & 60.21 & 527.3 & 60.90 \\
\hline & Young & 396.2 & 77.59 & 409.1 & 78.78 & 546.1 & 94.10 & 542.5 & 84.59 \\
\hline \multicolumn{10}{|c|}{ Subliminal } \\
\hline & Older & 379.0 & 67.82 & 403.9 & 80.16 & 502.7 & 86.61 & 541.0 & 86.08 \\
\hline
\end{tabular}


Table 2

Descriptive Statistics for Young and Older Participants' RT (ms) on Each Gaze-cuing Task in Study 2

\begin{tabular}{|c|c|c|c|c|c|c|c|c|c|c|}
\hline \multirow[b]{3}{*}{ Task } & \multirow[b]{3}{*}{ Face Age } & \multirow[b]{3}{*}{ Face Emotion } & \multicolumn{4}{|c|}{ Young participants } & \multicolumn{4}{|c|}{ Older participants } \\
\hline & & & \multicolumn{2}{|c|}{ Congruent } & \multicolumn{2}{|c|}{ Incongruent } & \multicolumn{2}{|c|}{ Congruent } & \multicolumn{2}{|c|}{ Incongruent } \\
\hline & & & $M$ & $S D$ & $M$ & $S D$ & $M$ & $S D$ & $M$ & $S D$ \\
\hline \multirow{4}{*}{ Supralimiı } & & Happy & 393.4 & 74.81 & 410.7 & 65.82 & 563.2 & 200.18 & 569.1 & 204.46 \\
\hline & Young & & 396.5 & 72.58 & 414.1 & 78.09 & 558.1 & 212.96 & 580.0 & 199.22 \\
\hline & & Happy & 397.4 & 75.08 & 414.5 & 59.87 & 562.7 & 221.12 & 575.0 & 202.22 \\
\hline & Older & Fearful & 394.6 & 71.09 & 407.5 & 68.96 & 561.1 & 204.45 & 570.6 & 201.17 \\
\hline \multirow{4}{*}{ Sublimin } & Youn & Happy & 389.5 & 51.05 & 394.3 & 58.76 & 552.7 & 144.27 & 559.2 & 158.14 \\
\hline & & Fearful & 395.7 & 52.39 & 399.3 & 59.54 & 552.5 & 170.16 & 571.0 & 145.26 \\
\hline & & Нарру & 389.5 & 53.71 & 406.2 & 55.03 & 552.5 & 149.07 & 559.8 & 153.58 \\
\hline & Older & Fearful & 392.4 & 52.06 & 399.4 & 53.49 & 551.6 & 160.89 & 563.6 & 146.37 \\
\hline
\end{tabular}


Table 3

Young and Older Participants' Study 2 Ratings of Emotional Intensity in Gaze-cue Faces

\begin{tabular}{|c|c|c|c|c|c|}
\hline \multirow[b]{2}{*}{ Emotion } & \multirow[b]{2}{*}{ Gaze-cue face } & \multicolumn{2}{|c|}{ Young participants } & \multicolumn{2}{|c|}{ Older participants } \\
\hline & & $\mathbf{M}$ & SD & $\mathbf{M}$ & SD \\
\hline \multirow{2}{*}{ Нарру } & Young & 5.3 & .74 & 5.5 & .98 \\
\hline & Older & 5.2 & .71 & 5.4 & 1.14 \\
\hline \multirow{2}{*}{ Fearful } & Young & 4.3 & 1.16 & 4.5 & 1.31 \\
\hline & Older & 4.1 & 1.01 & 4.5 & 1.08 \\
\hline
\end{tabular}

Note. Ratings range from 1 (Not at all happy/scared) to 7 (Very happy/scared). 